\title{
Pharmacodynamic analysis of target-controlled infusion of propofol in patients with hepatic insufficiency
}

\author{
JING-RU PAN, JUN CAI, SHAO-LI ZHOU, QIAN-QIAN ZHU, \\ FEI HUANG, YI-HAN ZHANG, XIN-JIN CHI and ZI-QING HEI \\ Department of Anesthesiology, Third Affiliated Hospital, \\ Sun Yat-sen University, Guangzhou, Guangdong 510630, P.R. China
}

Received June 7, 2016; Accepted September 16, 2016

DOI: $10.3892 /$ br.2016.786

\begin{abstract}
The effect of liver dysfunction on target-controlled infusion (TCI) of propofol remains poorly documented. The pharmacodynamic performance of propofol TCI was evaluated in a cohort of Chinese patients with hepatic insufficiency. Fifty-three patients with hepatic insufficiency were enrolled in the current prospective, observational study. Anesthesia was induced with propofol via TCI to a plasma concentration of $3 \mu \mathrm{g} / \mathrm{ml}$. Following loss of consciousness (LOC), fentanyl and cisatracurium were administered. Pharmacodynamic parameters were recorded during TCI, including time to LOC, bispectral index (BIS), heart rate (HR) and blood pressure. Patients were divided into two groups based on model of end stage liver disease (MELD) score: Those with a MELD score of $\leq 9$ and those with a MELD score of $\geq 10$. BIS, mean arterial pressure and HR were demonstrated to vary according to time, but were not affected by liver dysfunction. Hypotension was prominent in patients with a MELD score of $\geq 1030$ min after induction. The proportion of bradycardia and hypotension at the other time points was not significantly different between MELD scores of $\leq 9$ and $\geq 10$. Notably, no bradycardia was observed in MELD of $\geq 10$. Thus, bradycardia and hypotension was observed in patients with hepatic insufficiency over time, although patients with different severities of hepatic insufficiency did not present with different depths of anesthesia. TCI of propofol to $3 \mu \mathrm{g} / \mathrm{ml}$ may be not suitable for patients with hepatic insufficiency, particularly those with severe liver dysfunction. Predictive concentrations (Cp) of TCI propofol requires further investigation and adjustment
\end{abstract}

Correspondence to: Dr Xin-Jin Chi or Dr Zi-Qing Hei, Department of Anesthesiology, Third Affiliated Hospital, Sun Yat-sen University, 600 Tianhe Road, Guangzhou, Guangdong 510630, P.R. China

E-mail: chixinjin@yeah.net

E-mail: heiziqing@sina.com

Key words: target-controlled infusion, propofol, liver dysfunction, pharmacodynamics in patients with hepatic insufficiency (trial registration no. ChiCTR-OCH-12002255).

\section{Introduction}

Target-controlled infusion (TCI) is an intravenous administration system, which provides desired target plasma concentrations of therapeutic agents and aims to maintain an appropriate depth of anesthesia (1-5). TCI has become increasingly popular in clinical practice, due to its ability to maintain more consistent plasma concentrations with fewer fluctuations (6), the smooth process of induction (7) and easily adjustable depth of anesthesia (8), as well as more predictable recovery time (9). The Marsh pharmacokinetic parameters (10) that are incorporated into the Diprifusor TCI system were derived from a relatively small number of healthy individuals without organs dysfunction (11). These parameters have been proven to provide a stable blood-therapeutic agent concentration for propofol induction and maintenance of anesthesia in patients without organ dysfunction (10,12-14).

Propofol is widely administered in clinical practice for induction and maintenance of anesthesia due to its rapid onset of action, large volume of distribution and high-clearance rate (15-17). The pharmacokinetics of propofol are dependent on the liver in multiple ways. Previous studies demonstrated that propofol could be viewed as an acceptable choice for patients with liver dysfunction, as it was proven to be safe in patients with moderate cirrhosis undergoing gastrointestinal endoscopy $(18,19)$, and displayed a protective, antioxidant-like effect on liver damage and dysfunction, as well as ischemic reperfusion injury in liver transplant recipients $(20,21)$. However, the free fraction of the therapeutic agent in circulation depends on the liver's synthetic ability to produce albumin (22) and its clearance is also dependent on hepatic metabolism (23). Therefore, the actual propofol concentrations that are administrated via Diprifusor TCI, where the parameters are derived from healthy individuals, may be higher than expected due to decreased hepatic function and should not be overlooked in patients with hepatic insufficiency.

Thus, the metabolism of propofol is predominantly reliant on the liver; therefore, the reliability of TCI of propofol in patients with hepatic insufficiency remains largely unknown. Whether TCI of propofol to $3 \mu \mathrm{g} / \mathrm{ml}$, which is recommended 
to patients without severe liver dysfunction, is suitable for patients with liver dysfunction during induction and intubation remains unclear. Thus, the purpose of the current study was to assess the performance of induction, via hemodynamics and the depth of anesthesia during TCI of propofol to $3 \mu \mathrm{g} / \mathrm{ml}$, in patients with varying degrees of liver dysfunction.

\section{Materials and methods}

Ethical approval. Ethical approval for the current study was provided by the Ethics committee of the Third Affiliated Hospital, Sun Yat-sen University (Guangzhou, China). Written informed consent was obtained from all patients prior to commencing the investigations (Trial registration no. ChiCTR-OCH-12002255).

Selection and description of participants. Fifty-three (45 males and 7 females) consecutive patients (aged, 18-65 years), with cirrhosis or hepatic carcinoma, who were scheduled for elective liver transplantation, partial hepatectomy or splenectomy from the Third Affiliated Hospital, Sun Yat-sen University (Guangzhou, China), between June 2014 and June 2015 were recruited for this prospective observational study. Exclusion criteria included a history of serious impairment in respiratory, cardiovascular, renal and central nervous systems, and long-term use of mental or neurological drugs.

Administration of anesthesia. No premedication was provided. Heart rate (HR), peripheral arterial oxygen saturation $\left(\mathrm{SpO}_{2}\right)$, invasive arterial pressure and central venous pressure were continuously monitored (IntelliVue MP60; Philips Medizin Systeme Boeblingen GmbH, Boeblingen, Baden-Wurttemberg, Germany).

Prior to induction, patients were intravenously administered with Plasma-Lyte A in order to maintain a steady state from induction to the time just prior to commencing surgery. General anesthesia was induced with TCI propofol [Diprivan (200 mg/20 ml); Corden Pharma S.P.A., Caponago, Milano, Italy] set at a plasma target concentration of $3 \mu \mathrm{g} / \mathrm{ml}$. Following loss of consciousness (LOC), tracheal intubation was facilitated with $0.2 \mathrm{mg} / \mathrm{kg}$ cisatracurium [Cisatracurium Besilate (10 mg); Jiangsu Hengrui Medicine Co., Ltd., Lianyungang, China] and $4.0 \mu \mathrm{g} / \mathrm{kg}$ fentanyl [Fentanyl Citrate (0.1 mg/2 ml); Yichang Humanwell Pharmaceutical Co., Ltd., Yichang, China]. Lungs were mechanically ventilated with $50 \%$ oxygen to maintain the partial pressure of carbon dioxide between $30-35 \mathrm{mmHg}$. The propofol infusion was discontinued $30 \mathrm{~min}$ after its administration and surgery was then performed. Thereafter, anesthesia was maintained with sevoflurane [Sevofrane $(250 \mathrm{ml})$; Maruishi Pharmaceutical Co., Ltd., Chuoku, Osaka, Japan] inhalation. A bolus dose of cisatracurium $(5 \mathrm{mg})$ and fentanyl $(50 \mu \mathrm{g})$ was administered when necessary. All data were collected just before starting surgeries.

On occasion, bolus doses of either $50 \mu \mathrm{g}$ phenylephrine [Phenylephrine Hydrochloride (10 mg/1 ml); Shanghai Harvest Pharmaceutical Co., Ltd., Shanghai, China] or $5 \mathrm{mg}$ urapidil [Urapidil Hydrochloride $(25 \mathrm{mg} / 5 \mathrm{ml})$; Takeda $\mathrm{GmbH}$, Konstanz, Freiburg, Germany] were administered to maintain the mean arterial pressure (MAP) within a physiological range. Hypotension was defined as a $30 \%$ decrease in MAP and was treated with an intravenous bolus of phenylephrine $(24,25)$. Atropine was administered at doses of $0.25 \mathrm{mg}$ to maintain $\mathrm{HR} \geq 50 \mathrm{bpm}$ and doses were repeated as necessary.

Data collection. HR, MAP and bispectral index (BIS) were monitored and recorded at the following measurement time points: Before the study (baseline), and 1, 2, 5, 10, 20 and $30 \mathrm{~min}$ after drug administration. In addition, time to LOC (defined as the interval between the start of TCI and loss of responsiveness to a verbal command to open the eyes, which was assessed every $5 \mathrm{sec}$ ) and propofol consumption until LOC were recorded.

The primary outcomes of the study were fluctuation of intraoperative hemodynamics, defined by changes of HR, MAP, and the occurrence of hypotension and bradycardia during induction, and changes of BIS. Additional outcomes were time to LOC and the administration of vasoactive drugs.

Statistical analysis. Data were expressed as means \pm standard deviation, median (25th percentile, 75 th percentile), n (\%), or $\mathrm{n} /$ total number (\%), and analyzed using SPSS version 12.0 software package (SPSS, Inc., Chicago, IL, USA). General information was analyzed with either one-way analysis of variance (ANOVA) or Fisher's exact test. The time to LOC, dosage of propofol until LOC, dosage of phenylephrine and atropine were analyzed using the Wilcoxon signed-rank test. MAP, HR and BIS were analyzed with using measures ANOVA. The ratios of hypotension and bradycardia were analyzed with Fisher's exact test. $\mathrm{P}<0.05$ was considered to indicate a statistically significant difference.

\section{Results}

Grouping and characteristics of patients. Fifty-three patients exhibiting hepatic insufficiency were enrolled in the current study. A previous study revealed that patients with a model of end stage liver disease (MELD) score $<9$ experienced a mortality rate of $1.9 \%$ at 3 months, whereas those with a MELD score $>10$, were associated with a mortality rate that was increased by more than three times, and increased exponentially as the MELD score increased (26). Accordingly, the patients were divided into two groups based on MELD score (min., -1, max., 33) as follows: 32 patients were enrolled in the group with a MELD score of $\leq 9$ and 21 were enrolled in the group with a MELD score of $\geq 10$. Patient characteristics were comparable between the two groups, except for MELD score (Table I). Furthermore, the types of disease and surgery are presented in Table I.

Time to LOC and BIS changes subsequent to TCI with equal concentrations of propofol. Liver dysfunction affected neither the time nor the dosage of propofol until LOC (Table I). In addition, repeated measures ANOVA indicated that BIS was impacted by time, but not by liver dysfunction (Fig. 1).

Changes of MAP and HR subsequent to TCI with equal concentrations of propofol. During TCI, the MAP and HR of all patients significantly decreased subsequent to induction 
Table I. Characteristics of the patients.

\begin{tabular}{lcc}
\hline Characteristics & $\begin{array}{c}\text { MELD, } \leq 9 \\
{[\mathrm{n}=32(60.38 \%)]}\end{array}$ & $\begin{array}{c}\text { MELD }, \geq 10 \\
{[\mathrm{n}=21(39.62 \%)]}\end{array}$ \\
\hline Age (years) & $46.44 \pm 7.26$ & $50.50 \pm 8.64$ \\
Gender (male/female) & $27 / 5$ & $19 / 2$ \\
Body mass index & $21.75 \pm 2.80$ & $22.19 \pm 3.19$ \\
MELD score & $5.19 \pm 2.74$ & $16.71 \pm 8.09$ \\
Median (25th percentile, & $5.5(4.0,7.8)$ & $11.0(11.0,23.5)$ \\
75 th percentile) & & \\
Types of disease & & \\
Cirrhosis & $19(59.38 \%)$ & $12(57.14 \%)$ \\
Hepatic carcinoma & $13(40.63 \%)$ & $9(42.86 \%)$ \\
Types of surgery & & \\
Liver transplantation & $5(15.63 \%)$ & $17(80.95 \%)$ \\
Partial hepatectomy & $19(59.68 \%)$ & $4(19.05 \%)$ \\
Splenectomy & $8(25.00 \%)$ & $0(0.00 \%)$ \\
Time to LOC (sec) & $77(62,142)$ & $84(58,129)$ \\
Dosage of propofol & $0.90(0.85,1.10)$ & $0.91(0.81,1.06)$ \\
until LOC (mg/kg) & & \\
\end{tabular}

The MELD score was calculated from the objective values of preoperative serum bilirubin, serum creatinine, and INR as follows: MELD score $=3.8 \times \ln ($ bilirubin $\mathrm{mg} / \mathrm{dl})+11.2 \times \ln (\mathrm{INR})+9.6 \times \ln ($ creatinine $\mathrm{mg} / \mathrm{dl})+6.4$. Data are expressed as means \pm standard deviation, or $\mathrm{n}(\%)$, or median (25th percentile, 75 th percentile). All variables were comparable in the two groups ( $\mathrm{P}>0.05)$. MELD, model of end stage liver disease; LOC, loss of consciousness; INR, international normalized ratio.

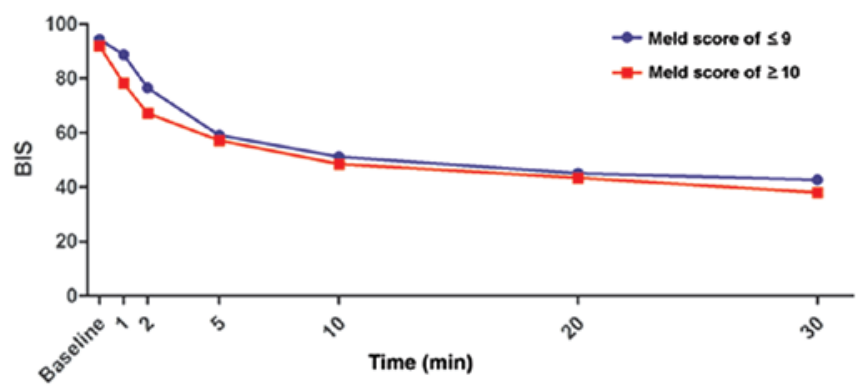

Figure 1. Changes in the BIS of the two groups during target-controlled infusion of propofol (plasma concentration, $3 \mu \mathrm{g} / \mathrm{ml}$ ). According to the mean value of each group at each time point, the trends of BIS significantly decreased following anesthesia induction $(\mathrm{P}<0.05)$. Repeated measures analysis of variance indicated that BIS was impacted by time, but there were no significant differences between the two groups at each time point. BIS bispectral index; MELD, model of end stage liver disease.

of anesthesia $(\mathrm{P}<0.05$; Fig. $2 \mathrm{~A}$ and $\mathrm{B})$. MAP or HR were not significantly different between the two MELD score groups $(\mathrm{P}>0.05)$.

Hypotension occurred 5 min after TCI of propofol in the two groups, although not in all of the patients. Furthermore, the proportion of hypotension was not significantly different between patients in the two groups, except for at $30 \mathrm{~min}$ (Table II).
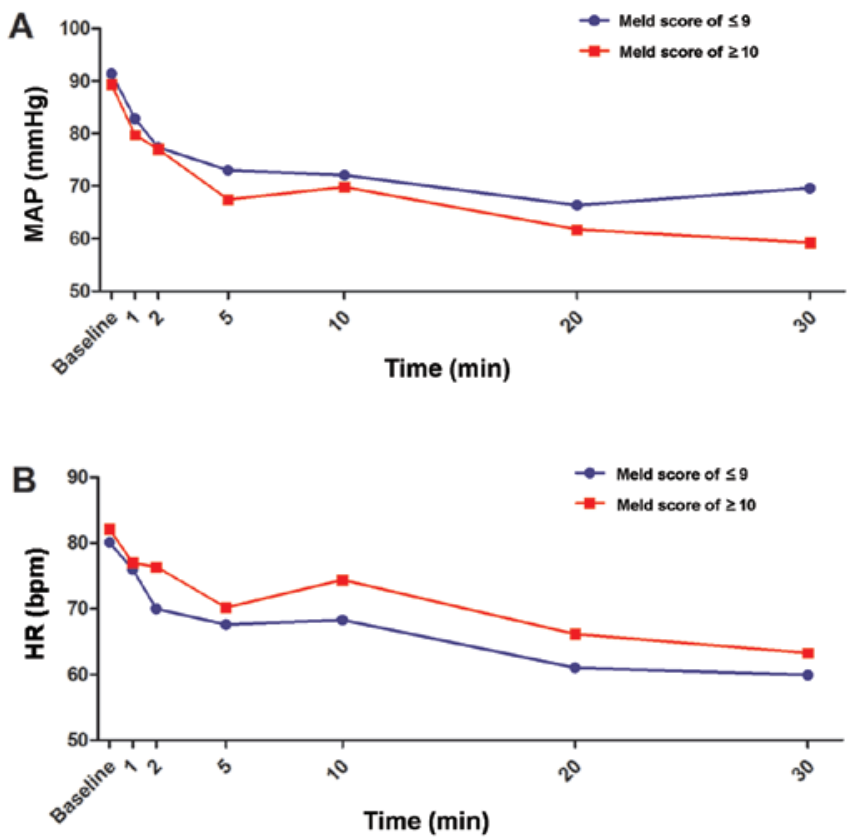

Figure 2. Changes in (A) MAP and (B) HR in the two groups during TCI of propofol. The trends of MAP and HR are presented as the mean value of each group at each time point. During TCI, the MAP and HR of all groups significantly decreased following anesthesia induction $(\mathrm{P}<0.05)$. Neither MAP nor HR were significantly different between the two MELD score groups. MAP, mean arterial pressure; HR, heart rate; TCI, target-controlled infusion.

The proportion of bradycardia was not significantly different between the two groups $(\mathrm{P}>0.05)$; however, it should be emphasized that there was no bradycardia observed in patients with MELD scores of $\geq 10$ (Table III). In addition, no differences were observed concerning the quantity of phenylephrine or atropine administered (Table IV).

\section{Discussion}

This prospective observational study assessed the differences of pharmacodynamics of TCI of $3 \mu \mathrm{g} / \mathrm{ml}$ propofol during induction and intubation in patients with varying degrees of liver dysfunction. The results of the current study demonstrated that the proportion of bradycardia and depth of anesthesia was not significantly different between the different MELD score groups. However, bradycardia and hypotension were observed, and the patients with severe liver dysfunction were more likely to develop into hypotension over time. These results provided novel evidence and a possible research direction for TCI of propofol in patients with hepatic insufficiency.

The TCI system is a frequently used device in daily clinical practice. Marsh parameters incorporated into the Diprifusor TCI system have been derived from subjects with normal liver function (27). In previous studies $(28,29)$, propofol predictive concentrations (Cp) set at $3 \mu \mathrm{g} / \mathrm{ml}$ provided effective conditions for intubation, stabilized hemodynamics and appropriate depth of anesthesia, whether the patients were adults or children, with mild or moderate liver disease (30). In line with these studies, the present study demonstrated that with the same induction program of TCI of propofol, the patients with different degrees of hepatic dysfunction experienced the same trend of depth of anesthesia. However, 
Table II. Proportion of hypotension.

\begin{tabular}{lccc}
\hline Time (min) & MELD, $\leq 9$ & MELD, $\geq 10$ & P-value \\
\hline 1 & $0 / 32$ & $0 / 21$ & - \\
& $(0)$ & $(0)$ & \\
2 & $0 / 32$ & $0 / 21$ & - \\
& $(0)$ & $(0)$ & \\
5 & $11 / 32$ & $9 / 21$ & 0.573 \\
& $(34.38)$ & $(42.86)$ & \\
10 & $5 / 32$ & $6 / 21$ & 0.310 \\
& $(15.63)$ & $(28.57)$ & \\
20 & $12 / 32$ & $13 / 21$ & 0.099 \\
& $(37.50)$ & $(61.90)$ & \\
30 & $11 / 32$ & $14 / 21$ & 0.027 \\
& $(34.38)$ & $(66.67)$ & \\
\hline
\end{tabular}

${ }^{a}$ Values are expressed as n/total number (\%). Hypotension was defined as a decrease in MAP of $>30 \%$ from baseline. MELD, mode of end stage liver disease.

Table III. Proportion of bradycardia. ${ }^{\mathrm{a}}$

\begin{tabular}{lccc}
\hline Time $(\mathrm{min})$ & MELD, $\leq 9$ & MELD, $\geq 10$ & P-value \\
\hline 1 & $0 / 32$ & $0 / 21$ & - \\
& $(0)$ & $(0)$ & \\
2 & $1 / 32$ & $0 / 21$ & 1.000 \\
& $(3.13)$ & $(0)$ & \\
5 & $2 / 32$ & $0 / 21$ & 0.512 \\
& $(6.25)$ & $(0)$ & \\
10 & $1 / 32$ & $0 / 21$ & 1.000 \\
& $(3.13)$ & $(0)$ & \\
20 & $2 / 32$ & $0 / 21$ & 0.512 \\
& $(6.25)$ & $(0)$ & \\
30 & $3 / 32$ & $0 / 21$ & 0.269 \\
& $(9.38)$ & $(0)$ & \\
\end{tabular}

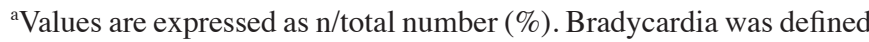
as heart rate $<50 \mathrm{bpm}$.

a recent study indicated that, to maintain similar depths of anesthesia, the propofol requirements administered by TCI were dependent on the severity of liver dysfunction (30). It was suggested that greater central nervous sensitivity to intravenous anesthetics was affected in certain ways by liver dysfunction, such as by progressive cognitive dysfunction or slowing of brain activity (31). Hepatic dysfunction has already been demonstrated to enhance sensitivity to sedative agents (32). Therefore, it was suggested that the exact dose of propofol, administered by TCI for appropriate depth of anesthesia in patients with severe impaired liver function, requires further investigation.
Table IV. Quantity of vasoactive therapeutic agents. ${ }^{a}$

\begin{tabular}{lccc}
\hline Therapeutic agent & MELD, $\leq 9$ & MELD, $\geq 10$ & P-value \\
\hline Phenylephrine $(\mu \mathrm{g})$ & $0.0(0.0,0.0)$ & $0.0(0.0,37.5)$ & 0.134 \\
& $17.19 \pm 51.76$ & $28.57 \pm 56.06$ & 0.399 \\
Atropine (mg) & $0.0(0.0,0.0)$ & $0.0(0.0,0.0)$ & 0.095 \\
& $0.04 \pm 0.13$ & 0.00 & 1.000
\end{tabular}

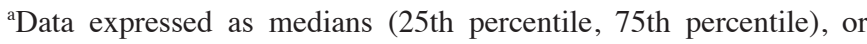
means \pm standard deviation.

MELD has been used as an objective scale of disease severity for management of patients with end-stage liver disease, and validated as a predictor of long-term survival or short-term mortality for patients with decompensated cirrhosis $(33,34)$. Thus, the present study classified patients according to MELD score. Furthermore, the MELD score includes renal function, which may be more suitable for assessing pharmacokinetics and pharmacodynamics of propofol in patients with hepatic insufficiency that is often accompanied by renal insufficiency. It has been widely recognized that the actual concentration of propofol in patients with severe liver dysfunction is higher $(35,36)$. The increased concentration of propofol did not lead to significant changes in the depth of anesthesia in the present study. However, the incidence of cardiovascular events tended to differ between the two groups, particularly hypotension. In the present study, the proportion of hypotension was significantly prominent in the MELD score of $\geq 10$ group when compared with the MELD score of $\leq 9$ group at $30 \mathrm{~min}$, but not at the other time points. Propofol exhibits suppressive cardiac effects, and the magnitude of hypotension depends on the drug concentration in plasma (37). A higher actual plasma concentration of propofol in more severe hepatic dysfunction was shown to suppress cardiac function more significantly (38). In the present study, the association of liver function with blood pressure (BP) became more significant over time, although the proportion of hypotension did not vary between the different severities of liver dysfunction during the first $20 \mathrm{~min}$. With regard to HRs, the proportion of bradycardia was not significantly different between patients in the two groups. It was, however, noteworthy that no bradycardia was observed in the MELD score of $\geq 10$ group. This was consistent with a previous study, which showed that propofol was often accompanied by a significant decrease in arterial BP and HR, while bradycardia and hypotension were not commonly associated (39). The lack of association between bradycardia and hypotension may be attributed to the cardiac depressor reflex, although the exact mechanism remains unclear.

China is one of the most highly endemic areas of the hepatitis virus infection, with an incidence of HBV infection of $>8 \%(40,41)$. Patients that are infected with the hepatitis virus may develop liver dysfunction to varying degrees. This may result in abnormal levels of serum albumin, bilirubin and coagulation, which affects the pharmacokinetics and pharmacodynamics of certain therapeutic agents. In the present study, the incidence of cardiovascular events in patients with liver dysfunction may potentially have resulted from a higher 
measured concentration than $\mathrm{Cp}$ of propofol. Although the liver dysfunction was moderate it should be acknowledged. The target concentration requires further investigation and adjustment, although a previous study reported that the pharmacokinetics and protein binding of propofol were not markedly affected by cirrhosis (42). Thus, the difference in pharmacokinetics of TCI of propofol in patients with liver dysfunction may explain the difference of pharmacodynamics; however, this requires further investigation in our future research.

There were certain limitations of the present study. First, the actual measured plasma concentration and pharmacokinetics were not analyzed at the same time, predominantly due to a limited observation time and lack of manpower. Secondly, the study observation time period in this current investigation was too short, limited to the period between anesthesia induction and surgery initiation. Third, the small number of patients may have reduced the power of the present results, which require clarification in a larger population.

In conclusion, the current study revealed that TCI of propofol to $3 \mu \mathrm{g} / \mathrm{ml}$ in patients with liver dysfunction did not result in a varying depth of anesthesia, while bradycardia and hypotension was observed in patients over time. It was suggested that TCI of propofol $\mathrm{Cp}$ requires investigation and adjustment in patients with hepatic insufficiency. A lower target concentration may be more suitable for this type of patients; however, further verification in future studies is required.

\section{References}

1. Anderson BJ: Pediatric models for adult target-controlled infusion pumps. Paediatr Anaesth 20: 223-232, 2010.

2. Fanti L, Agostoni M, Arcidiacono PG, Albertin A, Strini G, Carrara S, Guslandi M, Torri G and Testoni PA: Target-controlled infusion during monitored anesthesia care in patients undergoing EUS: propofol alone versus midazolam plus propofol. A prospective double-blind randomised controlled. Dig Liver Dis 39: 81-86, 2007.

3. Eriksson O, Josephsson R, Långstrom B and Bergström M: Positron emission tomography and target-controlled infusion for precise modulation of brain drug concentration. Nucl Med Biol 35: 299-303, 2008.

4. Lin BF, Huang YS, Kuo CP, Ju DT, Lu CH, Cherng CH and Wu CT: Comparison of A-line autoregressive index and observer assessment of alertness/sedation scale for monitored anesthesia care with target-controlled infusion of propofol in patients undergoing percutaneous vertebroplasty. J Neurosurg Anesthesiol 23: 6-11, 2011

5. Guo Z, Pang L, Jia X, Wang X, Su X, Li P, Mi W and Hao J: Intraoperative target-controlled infusion anesthesia application using remifentanil hydrochloride with etomidate in patients with severe burn as monitored using Narcotrend. Burns 41: 100-105, 2015.

6. Egan TD: Target-controlled drug delivery: Progress toward an intravenous 'vaporizer' and automated anesthetic administration. Anesthesiology 99: 1214-1219, 2003.

7. Hu LG, Pan JH, Li J, Kang F and Jiang L: Effects of different doses of sufentanil and remifentanil combined with propofol in target-controlled infusion on stress reaction in elderly patients. Exp Ther Med 5: 807-812, 2013.

8. Derrode N, Lebrun F, Levron JC, Chauvin M and Debaene B: Influence of peroperative opioid on postoperative pain after major abdominal surgery: Sufentanil TCI versus remifentanil TCI. A randomized, controlled study. Br J Anaesth 91: 842-849, 2003.

9. Kreuer S, Biedler A, Larsen R, Altmann S and Wilhelm W: Narcotrend monitoring allows faster emergence and a reduction of drug consumption in propofol-remifentanil anesthesia. Anesthesiology 99: 34-41, 2003.
10. Marsh B, White M, Morton N and Kenny GN: Pharmacokinetic model driven infusion of propofol in children. Br J Anaesth 67: 41-48, 1991.

11. Absalom AR, Mani V, De Smet T and Struys MM: Pharmacokinetic models for propofol - defining and illuminating the devil in the detail. Br J Anaesth 103: 26-37, 2009.

12. Coppens M, Van Limmen JG, Schnider T, Wyler B, Bonte S, Dewaele F, Struys MM and Vereecke HE: Study of the time course of the clinical effect of propofol compared with the time course of the predicted effect-site concentration: Performance of three pharmacokinetic-dynamic models. Br J Anaesth 104: 452-458, 2010.

13. Cortínez LI, De la Fuente N, Eleveld DJ, Oliveros A, Crovari F, Sepulveda P, Ibacache M and Solari S: Performance of propofol target-controlled infusion models in the obese: Pharmacokinetic and pharmacodynamic analysis. Anesth Analg 119: 302-310, 2014

14. Thomson AJ, Morrison G, Thomson E, Beattie C, Nimmo AF and Glen JB: Induction of general anaesthesia by effect-site target-controlled infusion of propofol: Influence of pharmacokinetic model and ke0 value. Anaesthesia 69: 429-435, 2014.

15. De Cosmo G, Congedo E, Clemente A and Aceto P: Sedation in PACU: The role of propofol. Curr Drug Targets 6: 741-744, 2005.

16. Vanlersberghe $\mathrm{C}$ and Camu F: Propofol. Handb Exp Pharmacol 182: 227-252, 2008.

17. Simoni RF, Esteves LO, Miziara LE, Cangiani LM, Alves GG, Romano AL, Hansen PÜ and Vianna PT: Clinical evaluation of two Ke0 in the same pharmacokinetic propofol model: Study on loss and recovery of consciousness. Rev Bras Anestesiol 61: 397-408, 2011

18. Sharma P, Singh S, Sharma BC, Kumar M, Garg H, Kumar A and Sarin SK: Propofol sedation during endoscopy in patients with cirrhosis, and utility of psychometric tests and critical flicker frequency in assessment of recovery from sedation. Endoscopy 43: 400-405, 2011.

19. Tsai HC, Lin YC, Ko CL, Lou HY, Chen TL, Tam KW and Chen CY: Propofol versus midazolam for upper gastrointestinal endoscopy in cirrhotic patients: A meta-analysis of randomized controlled trials. PLoS One 10: e0117585, 2015.

20. Laviolle B, Basquin C, Aguillon D, Compagnon P, Morel I, Turmel V, Seguin P, Boudjema K, Bellissant E and Mallédant Y: Effect of an anesthesia with propofol compared with desflurane on free radical production and liver function after partial hepatectomy. Fundam Clin Pharmacol 26: 735-742, 2012.

21. Tsai YF, Lin CC, Lee WC and Yu HP: Propofol attenuates ischemic reperfusion-induced formation of lipid peroxides in liver transplant recipients. Transplant Proc 44: 376-379, 2012.

22. Takizawa D, Sato E, Ito N, Ogino Y, Hiraoka H, Goto F, Cavaliere F, Conti G, Moscato U, Meo F, et al: Hypoalbuminaemia and propofol pharmacokinetics. Br J Anaesth 95: 559; author reply 559, 2005.

23. Sayama H, Takubo H, Komura H, Kogayu M and Iwaki M: Application of a physiologically based pharmacokinetic model informed by a top-down approach for the prediction of pharmacokinetics in chronic kidney disease patients. AAPS J 16: 1018-1028, 2014.

24. Klimscha W, Weinstabl C, Ilias W, Mayer N, Kashanipour A, Schneider B and Hammerle A: Continuous spinal anesthesia with a microcatheter and low-dose bupivacaine decreases the hemodynamic effects of centroneuraxis blocks in elderly patients. Anesth Analg 77: 275-280, 1993.

25. Biboulet P, Jourdan A, Van Haevre V, Morau D, Bernard N, Bringuier $S$ and Capdevila $X$ : Hemodynamic profile of target-controlled spinal anesthesia compared with 2 target-controlled general anesthesia techniques in elderly patients with cardiac comorbidities. Reg Anesth Pain Med 37: 433-440, 2012.

26. Wiesner R, Edwards E, Freeman R, Harper A, Kim R, Kamath P, Kremers W, Lake J, Howard T, Merion RM, et al; United Network for Organ Sharing Liver Disease Severity Score Committee: Model for end-stage liver disease (MELD) and allocation of donor livers. Gastroenterology 124: 91-96, 2003.

27. Eleveld DJ, Proost JH, Cortínez LI, Absalom AR and Struys MM: A general purpose pharmacokinetic model for propofol. Anesth Analg 118: 1221-1237, 2014.

28. Muñoz HR, Cortínez LI, Ibacache ME and León PJ: Effect site concentrations of propofol producing hypnosis in children and adults: Comparison using the bispectral index. Acta Anaesthesiol Scand 50: 882-887, 2006.

29. Liu HC, Li J, Yang B, Shangguan WN, Cai MY and Lian QQ: Effect of pediatric TCI system for propofol plus remifentanil in pediatric short-duration surgery with laryngeal mask airway anesthesia. Zhonghua Yi Xue Za Zhi 91: 595-599, 2011 (In Chinese). 
30. Wu J, Huang SQ, Chen QL and Zheng SS: The influence of the severity of chronic virus-related liver disease on propofol requirements during propofol-remifentanil anesthesia. Yonsei Med J 54: 231-237, 2013.

31. Felipo V: Hepatic encephalopathy: Effects of liver failure on brain function. Nat Rev Neurosci 14: 851-858, 2013

32. Haq MM, Faisal N, Khalil A, Haqqi SA, Shaikh H and Arain N: Midazolam for sedation during diagnostic or therapeutic upper gastrointestinal endoscopy in cirrhotic patients. Eur J Gastroenterol Hepatol 24: 1214-1218, 2012.

33. Dunn W, Jamil LH, Brown LS, Wiesner RH, Kim WR, Menon KV, Malinchoc M, Kamath PS and Shah V: MELD accurately predicts mortality in patients with alcoholic hepatitis. Hepatology 41: 353-358, 2005.

34. D'Amico G, Garcia-Tsao G and Pagliaro L: Natural history and prognostic indicators of survival in cirrhosis: A systematic review of 118 studies. J Hepatol 44: 217-231, 2006.

35. Servin F, Cockshott ID, Farinotti R, Haberer JP, Winckler C and Desmonts JM: Pharmacokinetics of propofol infusions in patients with cirrhosis. Br J Anaesth 65: 177-183, 1990.

36. Servin FS, Bougeois B, Gomeni R, Mentré F, Farinotti R and Desmonts JM: Pharmacokinetics of propofol administered by target-controlled infusion to alcoholic patients. Anesthesiology 99: 576-585, 2003.
37. Das S, Forrest $\mathrm{K}$ and Howell S: General anaesthesia in elderly patients with cardiovascular disorders: Choice of anaesthetic agent. Drugs Aging 27: 265-282, 2010.

38. Krag A, Bendtsen F, Dahl EK, Kjær A, Petersen CL and Møller S: Cardiac function in patients with early cirrhosis during maximal beta-adrenergic drive: A dobutamine stress study. PLoS One 9: e109179, 2014.

39. Hug CC Jr, McLeskey CH, Nahrwold ML, Roizen MF, Stanley TH, Thisted RA, Walawander CA, White PF, Apfelbaum JL, Grasela TH, et al: Hemodynamic effects of propofol: Data from over 25,000 patients. Anesth Analg 77 (Suppl 4): S21-S29, 1993.

40. Trépo C, Chan HL and Lok A: Hepatitis B virus infection. Lancet 384: 2053-2063, 2014

41. Gao S, Duan ZP and Coffin CS: Clinical relevance of hepatitis B virus variants. World J Hepatol 7: 1086-1096, 2015.

42. Servin F, Desmonts JM, Haberer JP, Cockshott ID, Plummer GF and Farinotti R: Pharmacokinetics and protein binding of propofol in patients with cirrhosis. Anesthesiology 69: 887-891, 1988. 